\title{
Intraplantar injection of linalool reduces paclitaxel-induced acute pain in mice
}

\author{
Soh Katsuyama ${ }^{1}$, Hikari Kuwahata ${ }^{2}$, Tomomi Yagi ${ }^{1}$, Yukinaga Kishikawa ${ }^{1}$, Takaaki Komatsu'², Tsukasa \\ SAKURADA ${ }^{2}$, and Hitoshi NAKAMURA ${ }^{1}$ \\ ${ }^{1}$ Department of Clinical Pharmaceutics, Tohoku Pharmaceutical University, 4-4-1 Komatsushima, Aoba-ku, Sendai 981-8558, Japan and \\ ${ }^{2}$ Department of Pharmacology, Daiichi College of Pharmaceutical Sciences, 22-1 Tamagawa-cho, Minami-ku, Fukuoka 815-8511, Japan \\ (Received 12 March 2012; and accepted 31 March 2012)
}

\begin{abstract}
Linalool is the principal component of many essential oils known to possess biological activities. We previously reported that intraplantar injection of linalool reduces the nociceptive response as assayed by the capsaicin test. In this study, we sought to determine whether intraplantar injection of linalool could influence the induction of acute pain (allodynia and hyperalgesia) by paclitaxel in mice. Paclitaxel is widely used in cancer chemotherapy for the treatment of solid tumors, but it sometimes induces moderate to severe acute pain. Paclitaxel administered intraperitoneally as a single dose of 5,10 or $20 \mathrm{mg} / \mathrm{kg}$ produced mechanical allodynia and hyperalgesia in mice. Paclitaxel-induced mechanical allodynia and hyperalgesia began 1 day after administration of paclitaxel and resolved within 7 days. Linalool injected into the hindpaw caused a significant reduction in paclitaxel-induced mechanical allodynia and hyperalgesia. Pretreatment with naloxone hydrochloride, an opioid receptor antagonist, or naloxone methiodide, a peripherally acting $\mu$-opioid receptor-preferring antagonist, significantly reversed linalool-induced antiallodynia and antihyperalgesia. Our results provide evidence for the involvement of peripheral opioids in antiallodynia and antihyperalgesia induced by linalool. These results suggest that activation of peripheral opioid receptors may play an important role in reducing paclitaxel-induced mechanical allodynia and hyperalgesia.
\end{abstract}

The major classes of antineoplastic agents - the vinca alkaloids, taxanes, bortezomib and platinum-derived compounds - are associated with the development of dose-limiting neuropathic pain $(12,32)$. Paclitaxel is a taxane chemotherapeutic commonly used for the treatment of solid tumors and ovarian and breast cancers. Paclitaxel acts as an antimitotic by stabilizing microtubules against disassembly, thus inhibiting the cell cycle in late mitosis and ultimately inducing apoptosis (30). Peripheral neuropathy sometimes oc-

Address correspondence to: Hitoshi Nakamura, Ph.D., Department of Clinical Pharmaceutics, Tohoku Pharmaceutical University, 4-4-1 Komatsushima, Aoba-ku, Sendai 981-8558, Japan

Tel: +81-22-727-0211, Fax: +81-22-727-0149

E-mail: nakamura@tohoku-pharm.ac.jp curs as a side-effect of chemotherapeutic treatment with paclitaxel and often manifests as bilateral pain in the extremities in a stocking and glove-type distribution (5). This pain can greatly reduce patients' quality of life and affect activities of daily living. Furthermore, paclitaxel therapy often results in acute pain $(16,21)$. Acute pain begins $1-3$ days after the commencement of treatment with paclitaxel, resolves within 7 days and affects mostly the large axial muscular and joint regions (15).

Paclitaxel-induced acute pain following paclitaxel infusion has commonly been treated with nonsteroidal antiinflammatory drugs, acetaminophen and opioid pain medications (15). In addition, ShakuyakuKanzo-To (a Japanese herb) (11), corticosteroids (17), antihistamines (18), opioids (29) and amifostine (10) have been investigated for the prevention 
and treatment of paclitaxel-induced acute pain although studies regarding their efficacy were not conclusive.

Linalool is the naturally occurring enantiomer of the monoterpene compound found in a volatile component of the essential oil extracted from aromatic plants, sage, lavender, rosewood, thyme and bergamot. As previously reported $(2,3,22-24),(-)$ linalool administration produces antiinflammatory and antinociceptive activities in several behavioral assays. We recently reported that subcutaneous (s.c.) injection of capsaicin into the hindpaw produced a short-lasting paw-licking/biting response, which was dose-dependently inhibited by intraplantarly administered linalool (28). However, the antinociceptive efficacy of intraplantar linalool on paclitaxel-induced mechanical allodynia and hyperalgesia is unknown.

The principal aim of this work was to test whether intraplantar injection of linalool would produce antinociception in the context of paclitaxel-induced acute pain (allodynia and hyperalgesia) in mice.

\section{MATERIALS AND METHODS}

Animals. Male ddY-strain mice (Japan SLC, Hamamatsu, Japan) weighing an average of $23-25 \mathrm{~g}$, at the time of testing, were used in these experiments. The mice were individually housed in a colony maintained in a controlled environment $(12 \mathrm{~h}$ light/ dark cycle, room temperature $23^{\circ} \mathrm{C}, 50-60 \%$ relative humidity). The animals had unlimited access to food pellets and water. All behavioral experiments took place during the light period between the hours of 10:00 and 16:00 in a quiet room. The animals belonging to the various treatment groups $(n=10$ each group) were tested in randomized order. All experiments followed the Guidelines on Ethical Standards for Investigation of Experimental Pain in Animals (35). Additionally, the study was approved by the Committees of Animal Care and Use of Tohoku Pharmaceutical University.

Materials. The following drugs and chemicals were used: ( \pm ) linalool (Nacalai Tesque, Kyoto, Japan), the anticancer drug paclitaxel (Bristol-Myers Squibb Company, Tokyo, Japan), naloxone hydrochloride and naloxone methiodide (Sigma Chemical Co., St. Louis, MO). Linalool was diluted in jojoba wax (Simmondsia chinensis) (K.S.A. International, Co. Ltd., Kanagawa, Japan) to give a total amount of $2.5-10 \mu \mathrm{g} / \mathrm{paw}$ (28). Jojoba wax alone did not affect paclitaxel-induced mechanical allodynia or hyperal- gesia. Paclitaxel, naloxone hydrochloride and naloxone methiodide were each dissolved in physiological saline $(0.9 \% \mathrm{wt} / \mathrm{vol})$ for injection.

Experimental protocol. Paclitaxel (1, 5, 10 or $20 \mathrm{mg} /$ $\mathrm{kg}$ ) or vehicle (saline) was singly injected intraperitoneally (i.p.) into the mice. The doses of paclitaxel were decided based on a previous report utilizing ddY-strain mice (11). Mechanical allodynia and hyperalgesia of the hindpaw were assessed using two von Frey filaments of different bending forces $(0.07$ and $1.4 \mathrm{~g}$ ). Briefly, mice were placed individually in a plastic cage with a wire mesh bottom. After mice had adapted to the testing environment for $60 \mathrm{~min}$, the von Frey filaments were pressed perpendicularly against the mid-plantar surface of the hind paw from below the mesh floor and held for 3-5 $\mathrm{s}$ with the filament slightly buckled. Lifting of the paw was recorded as a positive response. Stimulation of the same intensity, which was started with a $0.07 \mathrm{~g}$ von Frey filament, was applied to the point of bending ten times to the plantar surface of the left or right hind paw per mouse at intervals of $5 \mathrm{~s}$. The behavioral test was performed between the hours of $10: 00$ and $16: 00$. The test was performed for 2 days before the start of experiments to accustom the mice to the testing procedures. The effects of linalool on mechanical allodynia and hyperalgesia were measured 1 day after the paclitaxel injection. Linalool was injected s.c. into the plantar surface of the right hindpaw. The opioid receptor antagonist naloxone and its quaternary form naloxone methiodide were pre-injected i.p. $30 \mathrm{~min}$ before, or into the hindpaw 15 min before, intraplantar injection of linalool. In order to assess any possible effect of linalool diffusion into the periphery, linalool was injected s.c. into the plantar surface of the contralateral (left hindpaw) or ipsilateral paws. In all experiments the observer was unaware of the drug injected and its concentration. Intraplantar and i.p. injections were given in a volume of $20 \mu \mathrm{L} /$ site and $0.1 \mathrm{~mL} / 10 \mathrm{~g}$ of body weight, respectively.

Data analysis. Data are presented as means \pm S.E.M. Statistical differences between groups were assessed with a two-way ANOVA followed by Bonferroni's test. The level of statistical significance was set at $5 \%(P<0.05)$ in all experiments. 
(A) Mechanical allodynia

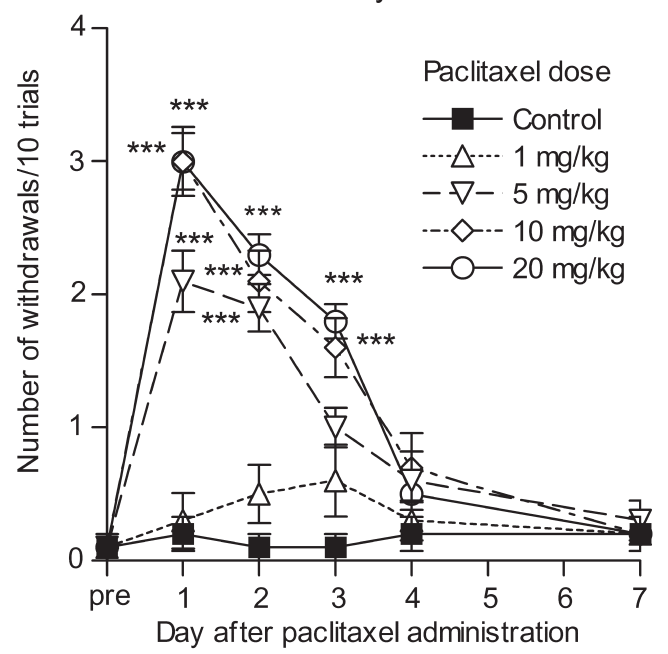

(B) Mechanical hyperalgesia

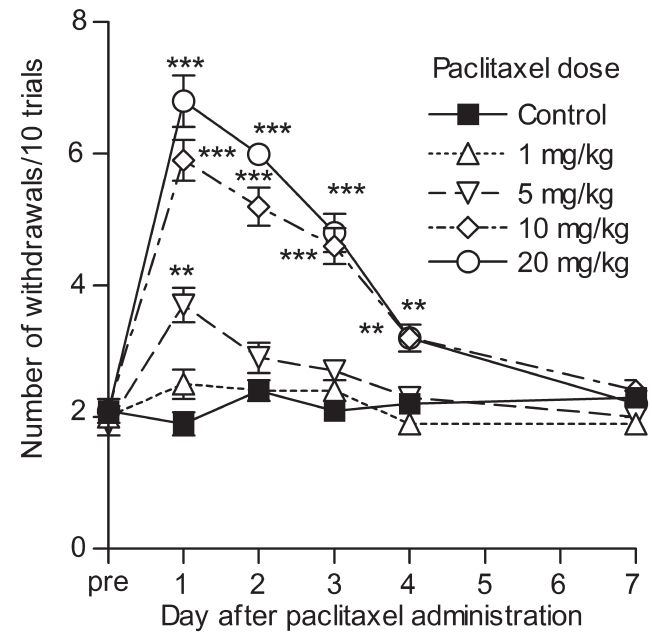

Fig. 1 Time course of mechanical allodynia (A) and hyperalgesia (B) induced by the administration of paclitaxel. Paclitaxel $(1,5,10$ or $20 \mathrm{mg} / \mathrm{kg})$ was intraperitoneally administered to mice. Mechanical allodynia (A) or hyperalgesia (B) were calculated as the mean \pm S.E.M. of 10 mice in each group. Significant differences between the groups were assessed with two-way ANOVA followed by Bonferroni's test. ${ }^{* *} P<$ $0.01,{ }^{\star * \star} P<0.001$ compared with the control group.

\section{RESULTS}

Paclitaxel-induced mechanical allodynia and hyperalgesia

Mechanical allodynia and hyperalgesia were not observed after paclitaxel was administered intraperitoneally at a dose of $1 \mathrm{mg} / \mathrm{kg}$. When the dose was increased to $5-20 \mathrm{mg} / \mathrm{kg}$, mechanical allodynia and hyperalgesia became marked (Fig. 1A and 1B). Thus, we subsequently used $20 \mathrm{mg} / \mathrm{kg}$ as the working dose of paclitaxel for inducing mechanical allodynia and

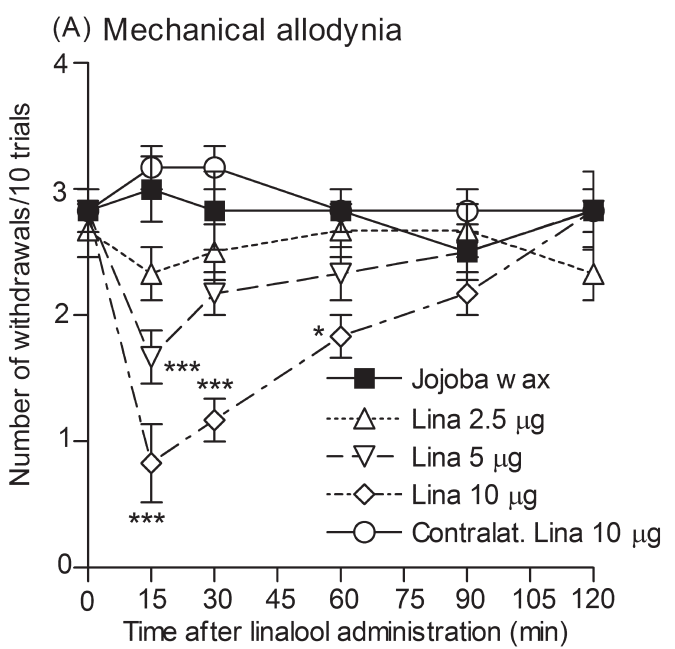

(B) Mechanical hyperalgesia

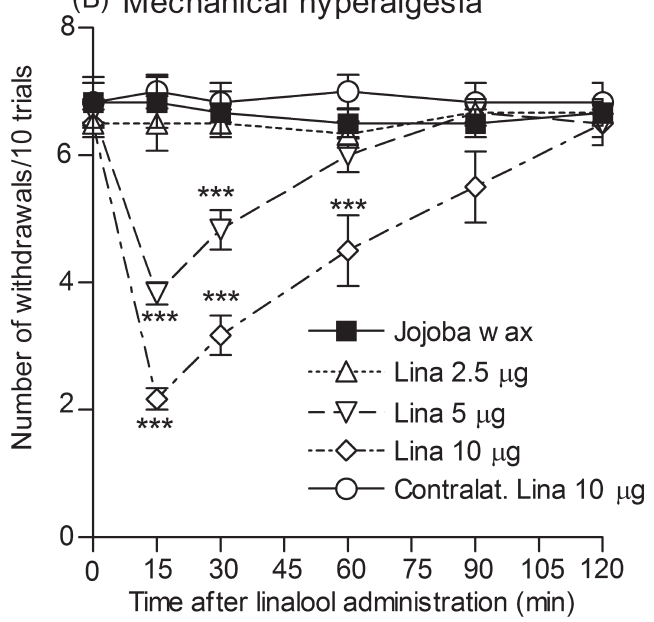

Fig. 2 Effects of linalool (Lina) injected into the hindpaw ipsilateral or contralateral (Contralat.) to the site of paclitaxel-induced mechanical allodynia (A) and hyperalgesia (B). Antiallodynic (A) or antihyperalgesic (B) effects were calculated as the mean \pm S.E.M. of 10 mice in each group. Significant differences between the groups were assessed with two-way ANOVA followed by Bonferroni's test. ${ }^{*} P<0.05$, ${ }^{\star * \star} P<0.001$ compared with the jojoba wax control.

hyperalgesia. At a dose of $20 \mathrm{mg} / \mathrm{kg}$ of paclitaxel, mechanical allodynia and hyperalgesia peaked 1 day after administration, and decreased gradually, almost subsiding by 7 days; mechanical allodynia and hyperalgesia were significant after 1,2 and 3 days compared to the control group. The effect of paclitaxel on the overall health of the mice appeared to be minimal. No mouse presented with weight loss or died within 7 days of administration.

Effects of locally administered linalool on paclitaxel-induced mechanical allodynia and hyperalgesia After injection of paclitaxel $20 \mathrm{mg} / \mathrm{kg}$, the mean 
(A) Mechanical allodynia
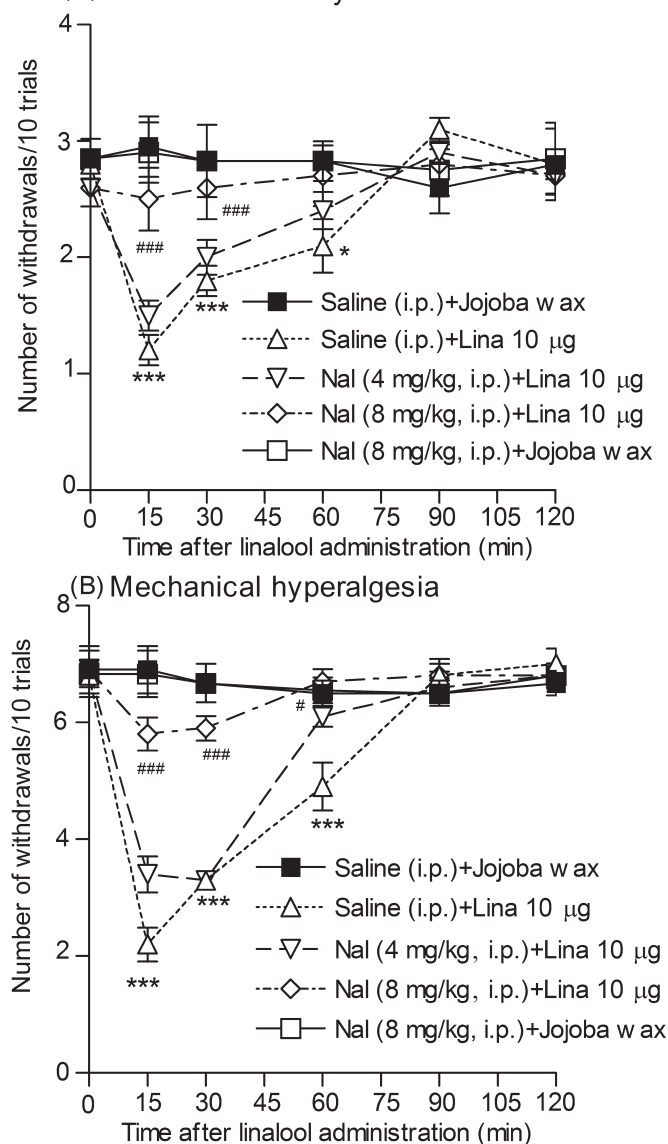

Fig. 3 Effects of i.p. injection of naloxone hydrochloride (Nal) on antiallodynia (A) or antihyperalgesia (B) induced by linalool (Lina). Nal was pre-injected i.p. 30 min before intraplantar injection of linalool. Values represent the mean \pm S.E.M. for 10 mice per group. Significant differences between the groups were assessed with two-way ANOVA followed by Bonferroni's test. ${ }^{\star} P<0.05$, ${ }^{\star \star \star} P<0.001$ compared with the saline (i.p.) + jojoba wax control. ${ }^{\#} P<0.05$, ${ }^{\# \#} P<$ 0.001 compared with the saline (i.p.) + Lina $10 \mu \mathrm{g}$ group.

right hindpaw mechanical threshold to pain decreased dramatically, reaching a minimum on day 1 (Fig. 1A and 1B), when tests to assess the effects of linalool were performed. Local intraplantar injection of linalool (5 and $10 \mu \mathrm{g} / \mathrm{paw}) 1$ day after paclitaxel injection significantly reversed paclitaxel-induced mechanical allodynia and hyperalgesia compared with the jojoba wax control group at 15 and $30 \mathrm{~min}$ after injection, whereas linalool $(2.5 \mu \mathrm{g} / \mathrm{paw})$ did not show any significant inhibitory effects on paclitaxelinduced pain (Fig. 2A and 2B). Jojoba wax control injections local to the paclitaxel injection site did not affect pain thresholds. To ensure that the effects of intraplantar injections of linalool were local and not due to systemic diffusion, linalool $(10 \mu \mathrm{g} / \mathrm{paw})$
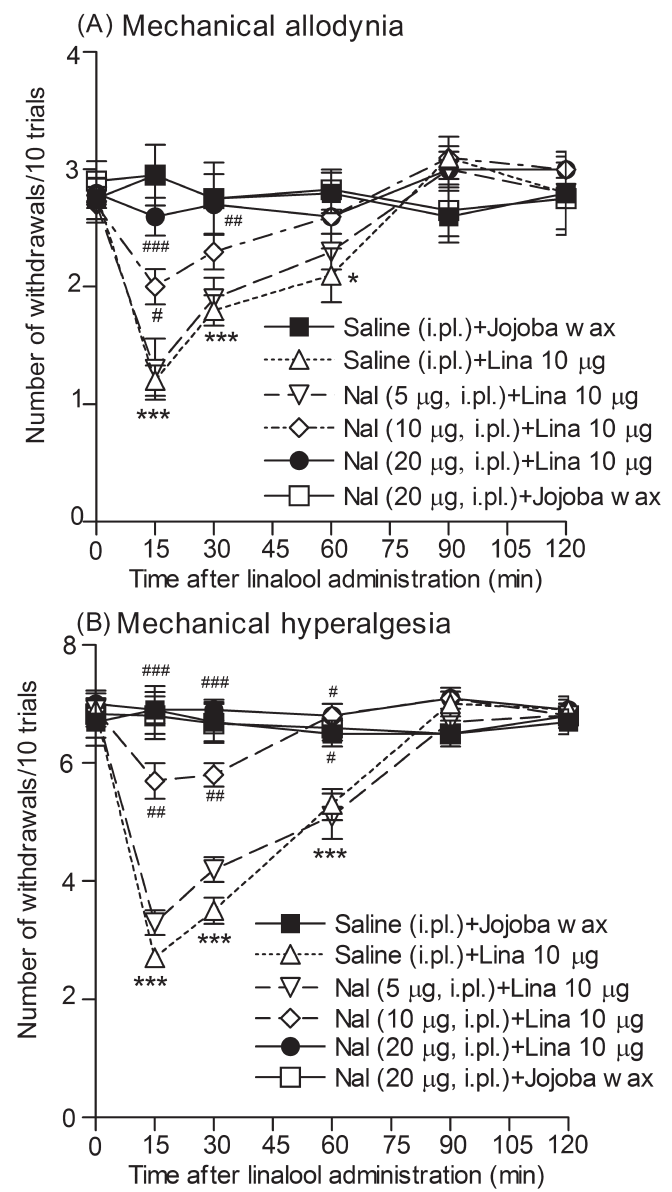

Fig. 4 Effects of intraplantar (i.pl.) injection of naloxone hydrochloride (Nal) on antiallodynia (A) or antihyperalgesia (B) induced by linalool (Lina). Nal was pre-injected into the hindpaw 15 min before intraplantar injection of linalool. Values represent the mean \pm S.E.M. for 10 mice per group. Significant differences between the groups were assessed with two-way ANOVA followed by Bonferroni's test. * $P<0.05$, ${ }^{* * *} P<0.001$ compared with the saline (i.pl.) + jojoba wax control. ${ }^{\#} P<0.05,{ }^{\# \#} P<0.01,{ }^{\# \# \#} P<0.001$ compared with the saline (i.pl.) + Lina $10 \mu \mathrm{g}$ group.

was injected into the contralateral hindpaw. The mechanical threshold following injection of linalool in the contralateral hindpaw was not statistically different from that in the jojoba wax control group (Fig. 2A and 2B).

Effects of naloxone hydrochloride on peripheral antiallodynia and antihyperalgesia induced by linalool To determine if the antiallodynic and antihyperalgesic effects of linalool with respect to paclitaxel-induced pain were mediated by peripheral opioid systems, 1 day after paclitaxel injection animals were pretreated i.p. with naloxone hydrochloride, $30 \mathrm{~min}$ before injection of linalool $(10 \mu \mathrm{g} / \mathrm{paw})$. The opioid 

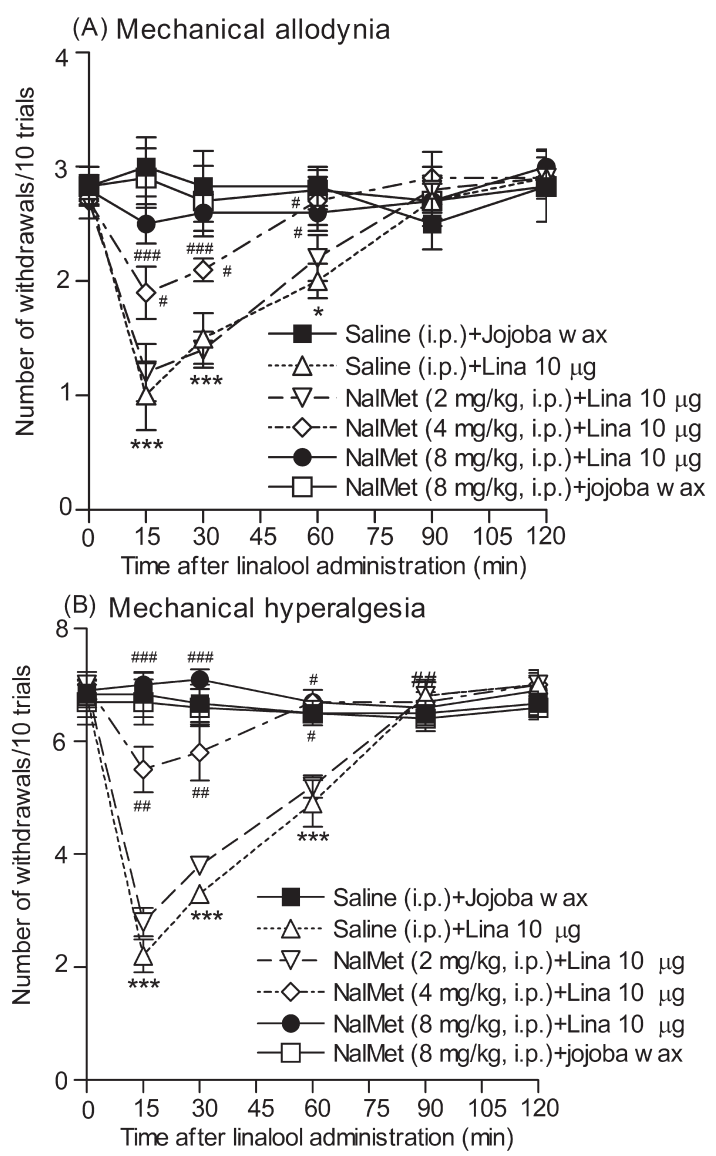

Fig. 5 Effects of i.p. injection of naloxone methiodide (NalMet) on antiallodynia (A) or antihyperalgesia (B) induced by linalool (Lina). NalMet was pre-injected i.p. 30 min before intraplantar injection of linalool. Values represent the mean \pm S.E.M. for 10 mice per group. Significant differences between the groups were assessed with two-way ANOVA followed by Bonferroni's test. ${ }^{*} P<0.05,{ }^{* \star *} P<0.001$ compared with the saline (i.p.) + jojoba wax control. ${ }^{\#} P<0.05$, ${ }^{\# \#} P<$ $0.01,{ }^{\# \# \#} P<0.001$ compared with the saline (i.p.) + Lina $10 \mu \mathrm{g}$ group.

receptor antagonist naloxone hydrochloride $(8 \mathrm{mg} /$ $\mathrm{kg}$, i.p.) significantly reversed the inhibitory effects of linalool on paclitaxel-induced allodynia and hyperalgesia (Fig. 3A and 3B). In further experiments, naloxone hydrochloride was injected directly into the same site on the hindpaw before intraplantar injection of linalool. Intraplantar pretreatment with naloxone hydrochloride $(20 \mu \mathrm{g} / \mathrm{paw})$ could also significantly antagonize the antiallodynic and antihyperalgesic effects of linalool (Fig. 4A and 4B).

Effects of naloxone methiodide on peripheral antiallodynia and antihyperalgesia induced by linalool Naloxone methiodide is thought to act on the peripheral opioid receptors as an antagonist (14). Pre- treatment with naloxone methiodide $(8 \mathrm{mg} / \mathrm{kg}$, i.p.) resulted in a significant antagonistic effect on linaloolinduced antiallodynia and antihyperalgesia (Fig. 5A and $5 \mathrm{~B})$.

\section{DISCUSSION}

The effect of linalool was investigated in a mouse paclitaxel-induced acute pain (allodynia and hyperalgesia) model. Intraplantar injection of linalool reduced behavioral signs of paclitaxel-induced mechanical allodynia and hyperalgesia in a dose-dependent manner. Linalool injected into the contralateral paw induced neither antiallodynia nor antihyperalgesia, even at a dose which was sufficient to induce antiallodynia and antihyperalgesia when injected into the ipsilateral paw. This finding suggests that linalool-induced antiallodynia and antihyperalgesia may be mediated locally rather than systemically. The present study further demonstrated that antiallodynia and antihyperalgesia induced by intraplantar linalool was antagonized by pretreatment with locally (plantar surface of the paw) administered naloxone hydrochloride and by the peripherally acting opioid receptor antagonist naloxone methiodide (14). These data suggest that intraplantar injection of linalool could produce peripheral antiallodynia and antihyperalgesia that is, at least in part, mediated through peripheral opioid mechanisms.

Recently, Hidaka et al. (11) reported that single i.p. administration at a dose of $10 \mathrm{mg} / \mathrm{kg}$ paclitaxel produced mechanical allodynia and hyperalgesia in male ddY-strain mice. In agreement with our study, following single i.p. administration of paclitaxel at a dose of $5-20 \mathrm{mg} / \mathrm{kg}$, mechanical allodynia and hyperalgesia peaked 1 day after administration and decreased gradually, almost subsiding by 7 days. Stimulation of the hindpaw with von Frey filaments of $0.07 \mathrm{~g}$ induced 2-3 withdrawals/10 trials (1 day). In contrast, in naïve mice, such stimuli did not induce any withdrawal response. Stimulation of the hindpaw of paclitaxel-treated animals with von Frey filaments of $1.4 \mathrm{~g}$ induced 4-7 withdrawals/10 trials ( 1 day). In contrast, in naïve mice, such stimuli induced only $1-2$ withdrawals/10 trials. The aversive behaviors induced by paclitaxel might represent mechanical hyperalgesia. Likewise, in our model, using $5-20 \mathrm{mg} / \mathrm{kg}$ of paclitaxel, mechanical allodynia and hyperalgesia peaked 1 day after single i.p. administration, decreased gradually, and had almost subsided by 7 days, which is similar to the classical arthralgias or myalgias seen in humans after paclitaxel therapy (15). Moreover, these time courses were 
similar to those for pain reported after paclitaxel administration in cancer patients $(6,15,19,20,27)$. Nonsteroidal antiinflammatory drugs, acetaminophen (15), Shakuyaku-Kanzo-To (a Japanese herb) (11), corticosteroids (17), antihistamines (18), opioids (29) and amifostine (10) have all been tested in the treatment of paclitaxel-induced acute pain but the findings of these studies have not been definitive.

Linalool has been shown to be effective as an antinociceptive compound in several nociceptive assays $(2,3,22-24)$. Linalool inhibited the biting response induced by intrathecal injection of IL-1 $\beta$ or TNF- $\alpha$ (2). Available evidence indicates that linalool could produce antinociception through interactions with opioid, muscarinic M2 or adenosine A1 receptors and nitric oxide (NO) synthesis $(22,24$ 26). In addition to these pharmacological data, there are also findings supporting the modulation of glutamatergic neurotransmission through $N$-methyl-D-aspartate (NMDA) receptors by linalool, both in vitro and in vivo $(1,4,7,8,31)$. Recently, we reported that intraplantar linalool administration reduced the nociceptive response as assayed by the capsaicin test. It has also been shown that the antinociceptive effects of linalool are antagonized by either direct injection of naloxone hydrochloride into the hindpaw or i.p. administration of naloxone methiodide, an antagonist acting at the peripheral opioid receptors (28).

The present data suggest that intraplantar injection of linalool significantly reduces paclitaxel-induced mechanical allodynia and hyperalgesia. Local injection of linalool into the contralateral hindpaw did not yield antinociceptive effects on paclitaxelinduced mechanical allodynia and hyperalgesia, strongly supporting a local effect of linalool on cutaneous nociceptors. In order to assess the possible participation of either opioid receptors or opioid peptides in intraplantar linalool-induced antiallodynia and antihyperalgesia, the effect of opioid receptor antagonists on the antiallodynic and antihyperalgesic activities of linalool was tested. The antiallodynic and antihyperalgesic effects produced by linalool were reversed by either i.p. or intraplantar pretreatment with naloxone hydrochloride. These results suggest that linalool-induced antiallodynia and antihyperalgesia may be mediated through opioid receptors in the periphery. This deduction is supported by the observation that pretreatment with the peripherally acting opioid receptor antagonist naloxone methiodide (14) resulted in a significant antagonistic effect on both antiallodynia and antihyperalgesia induced by intraplantar linalool.
It is conceivable that intraplantar linalool might cause the local release of endogenous opioid peptides and these might be responsible for the peripherally mediated antinociceptive effect. Keratinocytes are known to synthesize and secrete $\beta$-endorphin (33, $34)$. It is worth noting that proopiomelanocortin, the precursor of a variety of neuropeptides including $\beta$-endorphin $(9,13)$, is constitutively expressed by keratinocytes that are abundant in the skin.

In conclusion, single i.p. administration of paclitaxel at a dose of $5-20 \mathrm{mg} / \mathrm{kg}$ induced mechanical allodynia and hyperalgesia which reached maximal intensity 1 day after the administration, decreased gradually, and largely subsided by 7 days. This may prove to be a useful model of paclitaxel-induced acute pain and peripheral neuropathic pain. Our study showed that linalool reduced paclitaxelinduced acute pain (allodynia and hyperalgesia) in mice. The antiallodynic and antihyperalgesic effects of linalool were antagonized by the direct injection of naloxone hydrochloride into the hindpaw and i.p. naloxone methiodide, an antagonist acting at the peripheral opioid receptors. The present results indicate that linalool may be a promising therapeutic approach to managing paclitaxel-induced acute pain.

\section{REFERENCES}

1. Batista PA, Werner MF, Oliveira EC, Burgos L, Pereira P, Brum LF and Santos AR (2008) Evidence for the involvement of ionotropic glutamatergic receptors on the antinociceptive effect of (-)-linalool in mice. Neurosci Lett 440, 299-303.

2. Batista PA, Werner MF, Oliveira EC, Burgos L, Pereira P, Brum LF, Story GM and Santos AR (2010) The antinociceptive effect of (-)-linalool in models of chronic inflammatory and neuropathic hypersensitivity in mice. J Pain 11, 12221229.

3. Berliocchi L, Russo R, Levato A, Fratto V, Bagetta G, Sakurada S, Sakurada T, Mercuri NB and Corasaniti MT (2009) $(-)$-Linalool attenuates allodynia in neuropathic pain induced by spinal nerve ligation in $\mathrm{c} 57 / \mathrm{bl6}$ mice. Int Rev Neurobiol 85, 221-235.

4. Brum LF, Elisabetsky E and Souza D (2001) Effects of linalool on $\left[{ }^{3} \mathrm{H}\right] \mathrm{MK} 801$ and $\left[{ }^{3} \mathrm{H}\right]$ muscimol binding in mouse cortical membranes. Phytother Res 15, 422-425.

5. Dougherty PM, Cata JP, Cordella JV, Burton A and Weng HR (2004) Taxol-induced sensory disturbance is characterized by preferential impairment of myelinated fiber function in cancer patients. Pain 109, 132-142.

6. du Bois A, Lück HJ, Meier W, Adams HP, Möbus V, Costa S, Bauknecht T, Richter B, Warm M, Schröder W, Olbricht S, Nitz U, Jackisch C, Emons G, Wagner U, Kuhn W and Pfisterer J; Arbeitsgemeinschaft Gynäkologische Onkologie Ovarian Cancer Study Group (2003) A randomized clinical trial of cisplatin/paclitaxel versus carboplatin/paclitaxel as first-line treatment of ovarian cancer. J Natl Cancer Inst 95, 1320-1329.

7. Elisabetsky E, Marschner J and Souza DO (1995) Effects of 
linalool on glutamatergic system in the rat cerebral cortex. Neurochem Res 20, 461-465.

8. Elisabetsky E, Brum LF and Souza DO (1999) Anticonvulsant properties of linalool in glutamate-related seizure models. Phytomedicine 6, 107-113.

9. Galiegue S, Mary S, Marchand J, Dussossoy D, Carriere D, Carayon P, Bouaboula M, Shire D, Le Fur G and Casellas P (1995) Expression of central and peripheral cannabinoid receptors in human immune tissues and leukocyte subpopulations. Eur J Biochem 232, 54-61.

10. Gelmon K, Eisenhauer E, Bryce C, Tolcher A, Mayer L, Tomlinson E, Zee B, Blackstein M, Tomiak E, Yau J, Batist G, Fisher B and Iglesias J (1999) Randomized phase II study of high-dose paclitaxel with or without amifostine in patients with metastatic breast cancer. J Clin Oncol 17, 3038-3047.

11. Hidaka T, Shima T, Nagira K, Ieki M, Nakamura T, Aono Y, Kuraishi Y, Arai T and Saito S (2009) Herbal medicine Shakuyaku-kanzo-to reduces paclitaxel-induced painful peripheral neuropathy in mice. Eur J Pain 13, 22-27.

12. Kannarkat G, Lasher EE and Schiff D (2007) Neurologic complications of chemotherapy agents. Curr Opin Neurol 20, 719-725.

13. Khodorova A, Navarro B, Jouaville LS, Murphy JE, Rice FL, Mazurkiewicz JE, Long-Woodward D, Stoffel M, Strichartz GR, Yukhananov R and Davar G (2003) Endothelin-B receptor activation triggers an endogenous analgesic cascade at sites of peripheral injury. Nat Med 9, 1055-1061.

14. Lewanowitsch T and Irvine RJ (2002) Naloxone methiodide reverses opioid-induced respiratory depression and analgesia without withdrawal. Eur J Pharmacol 445, 61-67.

15. Loprinzi CL, Maddocks-Christianson K, Wolf SL, Rao RD, Dyck PJ, Mantyh P and Dyck PJ (2007) The Paclitaxel acute pain syndrome: sensitization of nociceptors as the putative mechanism. Cancer J 13, 399-403.

16. Loprinzi CL, Reeves BN, Dakhil SR, Sloan JA, Wolf SL, Burger KN, Kamal A, Le-Lindqwister NA, Soori GS, Jaslowski AJ, Novotny PJ and Lachance DH (2011) Natural history of paclitaxel-associated acute pain syndrome: prospective cohort study NCCTG N08C1. J Clin Oncol 29, 1472-1478.

17. Markman M, Kennedy A, Webster K, Kulp B, Peterson G and Belinson J (1999) Use of low-dose oral prednisone to prevent paclitaxel-induced arthralgias and myalgias. Gynecol Oncol 72, 100-101.

18. Martoni A, Zamagni C, Gheka A and Pannuti F (1993) Antihistamines in the treatment of taxol-induced paroxystic pain syndrome. J Natl Cancer Inst 85, 676.

19. McGuire WP, Hoskins WJ, Brady MF, Kucera PR, Partridge EE, Look KY, Clarke-Pearson DL and Davidson M (1996) Cyclophosphamide and cisplatin compared with paclitaxel and cisplatin in patients with stage III and stage IV ovarian cancer. $N$ Engl J Med 334, 1-6.

20. Ozols RF, Bundy BN, Greer BE, Fowler JM, Clarke-Pearson D, Burger RA, Mannel RS, DeGeest K, Hartenbach EM and Baergen R; Gynecologic Oncology Group (2003) Phase III trial of carboplatin and paclitaxel compared with cisplatin and paclitaxel in patients with optimally resected stage III ovarian cancer: a Gynecologic Oncology Group study. J Clin Oncol 21, 3194-3200.

21. Pachman DR, Barton DL, Watson JC and Loprinzi CL (2011)
Chemotherapy-induced peripheral neuropathy: prevention and treatment. Clin Pharmacol Ther 90, 377-387.

22. Peana AT, D'Aquila PS, Chessa ML, Moretti MD, Serra G and Pippia P (2003) (-)-Linalool produces antinociception in two experimental models of pain. Eur J Pharmacol 460, 3741.

23. Peana AT, D'Aquila PS, Panin F, Serra G, Pippia P and Moretti MD (2002) Anti-inflammatory activity of linalool and linalyl acetate constituents of essential oils. Phytomedicine 9, 721-726.

24. Peana AT, De Montis MG, Nieddu E, Spano MT, D’Aquila PS and Pippia P (2004) Profile of spinal and supra-spinal antinociception of (-)-linalool. Eur J Pharmacol 485, 165174.

25. Peana AT, Marzocco S, Popolo A and Pinto A (2006) (-)-Linalool inhibits in vitro NO formation: probable involvement in the antinociceptive activity of this monoterpene compound. Life Sci 78, 719-723.

26. Peana AT, Rubattu P, Piga GG, Fumagalli S, Boatto G, Pippia $\mathrm{P}$ and De Montis MG (2006) Involvement of adenosine A1 and A2 receptors in (-)-linalool-induced antinociception. Life Sci 78, 2471-2474.

27. Piccart MJ, Bertelsen K, James K, Cassidy J, Mangioni C, Simonsen E, Stuart G, Kaye S, Vergote I, Blom R, Grimshaw R, Atkinson RJ, Swenerton KD, Trope C, Nardi M, Kaern J, Tumolo S, Timmers P, Roy JA, Lhoas F, Lindvall B, Bacon M, Birt A, Andersen JE, Zee B, Paul J, Baron B and Pecorelli S (2000) Randomized intergroup trial of cisplatin-paclitaxel versus cisplatin-cyclophosphamide in women with advanced epithelial ovarian cancer: three-year results. $J$ Natl Cancer Inst 92, 699-708.

28. Sakurada T, Mizoguchi H, Kuwahata H, Katsuyama S, Komatsu T, Morrone LA, Corasaniti MT, Bagetta G and Sakurada S (2011) Intraplantar injection of bergamot essential oil induces peripheral antinociception mediated by opioid mechanism. Pharmacol Biochem Behav 97, 436-443.

29. Sarris AH, Younes A, McLaughlin P, Moore D, Hagemeister F, Swan F, Rodriguez MA, Romaguera J, North L, Mansfield P, Callendar D, Mesina O and Cabanillas F (1996) Cyclosporin A does not reverse clinical resistance to paclitaxel in patients with relapsed non-Hodgkin's lymphoma. J Clin Oncol 14, 233-239.

30. Schiff PB and Horwitz SB (1980) Taxol stabilizes microtubules in mouse fibroblast cells. Proc Natl Acad Sci USA 77, 1561-1565.

31. Silva Brum LF, Emanuelli T, Souza DO and Elisabetsky E (2001) Effects of linalool on glutamate release and uptake in mouse cortical synaptosomes. Neurochem Res 26, 191-194.

32. Windebank AJ and Grisold W (2008) Chemotherapy-induced neuropathy. J Peripher Nerv Syst 13, 27-46.

33. Wintzen M, Yaar M, Burbach JP and Gilchrest BA (1996) Proopiomelanocortin gene product regulation in keratinocytes. J Invest Dermatol 106, 673-678.

34. Zanello SB, Jackson DM and Holick MF (1999) An immunocytochemical approach to the study of beta-endorphin production in human keratinocytes using confocal microscopy. Ann N Y Acad Sci 885, 85-99.

35. Zimmermann M (1983) Ethical guidelines for investigation of experimental pain in conscious animals. Pain 16, 109110. 